\title{
Potential Diagnostic and Prognostic Values of Hematological Biomarkers in COVID-19
}

\author{
Hamzullah Khan', Shahtaj Khan ${ }^{2}$ \\ ${ }^{1}$ Department of Hematology, Nowshera Medical College, Nowshera/PGR HMC, \\ Peshawar \\ ${ }^{2}$ Department of Hematology, Hayatabad Medical Complex \\ Peshawar.
}

Corresponding Author Hamzullah khan

\section{Mobile: \\ 0334-4802902}

E mail:

hamzakmc@gmail.com

Key words: COVID-19, Pandemic, ROC Curve, Mortality
Background and study aims: COVID19 has spread around the globe in short span of time. We have been working as team to observe the pandemic since it hits our country and have been observing the different demographic, hematologic and inflammatory mediators that affect the outcome of the disease. To facilitate the clinicians working in isolation units and COVID-ICU, we tried to determine the clinical sensitivity of different hematological indices to predict the severity and mortality in COVID- 19.

Patients and Method: We did a cross sectional study covering 182 patients, $112(61.53 \%)$ males and 70(38.46\%) females, who were tested COVID-19 positive in two tertiary care hospitals of Khyber Pukhtunkhwa (Qazi Hussain Ahmed Medical Complex Nowshera \& Hayatabad Medical Complex Peshawar). Hematological markers were assessed for their diagnostic and prognostic values. Independent t-test was used in groups with different outcome (discharged satisfactorily vs expired) regarding hemoglobin concentration, neutrophil to lymphocyte ratio (NLR), absolute neutrophilic count (ANC) and platelet count.

\section{INTRODUCTION}

The last few decades are proved to have been worst for human lives around the globe [1]. SARS-COV-2 is the third virus that causes fatal respiratory disease in humans. The recent deadly pandemic of a new respiratory virus called COVID-19, was first reported from the city of Wuhan, China. Corona virus disease demonstrated its strong and rapid epidemic potential with spread
Receiver operating characteristics (ROC) curve was used as statistical tool to determine the relationship of clinical sensitivity and specificity of different hematological indicators to predict the worst outcome in COVID-19.

Results: A statistically significant difference $(\mathrm{p}<0.05)$ exists between the groups (discharged satisfactorily vs Expired) regarding NLR, ANC and platelet count. NLR is most reliable hematological prognostic indicator in COVID-19 to predict mortality/worst outcome with an area under curve (AUC) of 0.68 on ROC. The clinical sensitivity of hematological markers on ROC curve was: $\mathrm{Hb} \%<11 \mathrm{~g} / \mathrm{dl} \quad(59.1 \%), \quad$ TLC $>7.2 \mathrm{k}$ (75.9\%), ANC $>3.9 \%(86.2 \%)$, ALC $<1.5$ $(44.8 \%), \quad$ NLR $>1.8 \quad(93.1 \%) \quad$ and PLT $<150 \mathrm{k}$ in $(65.5 \%)$.

Conclusion: The clinical sensitivity as measured by AUC for hematological markers i.e. NLR, ANC and platelet count is statistically significant and an abnormally elevated levels of hematological markers indicate the severity of the disease. Likewise leukocytosis, neutrophilia and lymphopenia, with high NLR and low platelet count are worst prognostic markers in COVID-19.

worldwide in just a span of two months period [2].

The World Health Organization (WHO) declared global emergency of COVID-19, due to rapid rise in cases of in China and many other countries by the mid of February 2020. By the date $20^{\text {th }}$ Feb 2020 the number of laboratory confirmed cases reached 60,000 in China with 1,700 deaths. 
Likewise by the start of March 2020 virus had reached more than 30 countries outside China [3].

Globally, since the 31st December 2019 and till date $\left(28^{\text {th }}\right.$ Nov 2020), a total of $61,715,119$ cases have been reported worldwide, in accordance with the definition of the Centre of Disease Control (CDC) of COVID-19 cases, with $1,444,235$ deaths [4]. By $29^{\text {th }}$ Nov 2020, the reported data from government sources in Pakistan declared 392,400 confirmed cases with 7942 deaths. Out of the total cases, 338000 cases are recovered so far and 1316 cases are under treatment in high dependency and intensive care units countrywide. In Khyber Pakhtunkhwa, the total number of corona cases is crossing 46604 with 1355 deaths [5]. The gold standard test for diagnosis of COVID-19 is RT-PCR that detects SARS-COV-2 in high sensitivity and specificity limits and is used for symptomatic patients in acute phases [6].

Increasing scientific research in field of COVID19 , the abnormalities in routine laboratory investigations, particularly the baseline investigation that is complete blood picture, has the potential to indicate the severity of the disease in a quick, easy, affordable, accessible and economical way and can give a way forward for the specific tests for diagnosis and prognosis of the disease [7]. Laboratory abnormalities in hematological indices are used for assessment of homeostasis, in order to know the impact of the COVID-19 on hematopoietic system and homeostasis which significantly suffer in this deadly disease [8].

Present study was designed to assess the clinical sensitivity of the different indices of peripheral blood test (Complete blood count/CBC) to predict the severity and mortality in COVID-19.

\section{MATERIALS AND METHODS}

The reports of CBC of 182 cases admitted in the COVID-19 isolation unit in two tertiary care hospital of Khyber Pukhtunkhwa (Qazi Hussain Ahmed Medical Complex Nowshera \& Hayatabad Medical Complex Peshawar) were analyzed from $1^{\text {st }}$ May 2020 to $30^{\text {th }}$ Aug 2020.

Ethical Approval was taken from Institutional Ethical Review Board of Nowshera Medical College Nowshera/Qazi Hussain Ahmed Medical Complex Nowshera via letter No- 111422/HD/QHAMC/NMC Dated $4^{\text {th }}$ April 2020 from the office of the Hospital Director. Verbal consent was taken from all the respondents, with confirmation that their confidentiality shall be maintained. Likewise the co-author obtained an ethical approval from HMC Peshawar on the research proposal of hematological and inflammatory markers and their impact on mortality in COVID-19 via Letter no 316/HEC/B\&PSC/2020 on $15^{\text {th }}$ May 2020.

This study was conducted in line with the research regulations, followed the sound medical practice, redetected human rights and also within the principles of declaration of Helsinki of World Medical Association.

Patients from whom nasopharyngeal swab was obtained and thereafter hospitalized with an initial diagnosis of the corona virus disease irrespective of age and gender were included in the study.

Patient admitted in isolation with no reports of PCR and CBC were excluded from the study. The technique for the blood sampling for the CBC test was to collect $3 \mathrm{ml}$ of venous blood by vein-puncture under aseptic techniques. The blood was added in an EDTA vacutainer at a concentration of $1.5 \mathrm{mg} / \mathrm{ml}$ and mixed gently. Complete blood count was calculated on five parts Sysmex differential hematology analyzer.

For analysis purposes the patients were grouped as following to determine the statistical significance in dichotomous groups.

1. Patients discharged versus patients expired

2. Gender groups (Male and females)

3. $\mathrm{Hb} \%<11 \mathrm{~g} / \mathrm{dl}$ and $>11 \mathrm{~g} / \mathrm{dl}$

4. TLC $\leq 11 \mathrm{k}$ and $>11 \mathrm{k}$

5. Platelet $\leq 150 \mathrm{k}$ and $>150 \mathrm{k}$

6. $\mathrm{ANC} \leq 3.9$ and $>3.9 \mathrm{k}$

7. $\mathrm{ALC} \leq 1.5 \mathrm{k}$ and $>1.5 \mathrm{k}$

8. $\mathrm{NLR} \leq 1.8$ and $>1.8$

Data was entered in the SPSS (IBM Corp, Armonk, NY, USA) version 25 for analysis. The normality of data distribution was determined by Shapiro wilk test.

Peripheral blood information's regarding $\mathrm{Hb} \%$ (g/dl), TLC (x10.e3/ul), ANC (x10.e3/ul), ALC (x10.e3/ul), NLR, Platelet count were compared in groups (discharged satisfactorily vs expired).

Independent $t$ test was used to determine the difference of the numerical variables. Nonparametric test i.e. Mann Whitney U Test was 
used where the data was not normally distributed.

Receiver operating characteristics (ROC) curve was used for estimation of the area under curve (AUC) to determine the relationship of clinical sensitivity of different hematological indicators and to predict the worst outcome in COVID-19. The sensitivity and specificity were calculated using diagnostic statistics with ROC curve and 95\% confidence interval. (Table 1, figure 1).

Some of the indicators like neutrophiliclymphocytic ratio (NLR) was calculated manually (N/L*100) from the CBC report.

\section{RESULTS}

In present study we determined the relationship of clinical sensitivity and specificity of different hematological indicators to predict the worst outcome in COVID-19. A total of 182 patients, $135(74.2 \%)$ males and 47(25.8\%) females were studied.
Furthermore NLR was main prognostic factor in COVID-19 to predict mortality/worst outcome with an Area Under curve on ROC of 0.68 followed by absolute neutrophilic count (ANC) with AUC value of 0.6 and Platelet count with AUC value of 0.55 on ROC. The AUC of the TLC was at margin line, while for hemoglobin, it was not statistically significant. (Figure 1).

Based on the difference in the clinical sensitivity on ROC curve, we also determined the values of the sensitivity, specificity in comparison with RT-PCR. The sensitivity pattern of different hematological parameter as diagnostic marker in COVID-19 were: $\mathrm{Hb} \%<11 \mathrm{~g} / \mathrm{dl} \quad(59.1 \%)$, TLC $>11 \mathrm{k} \quad(75.9 \%), \quad$ ANC $>3.9 \% \quad(86.2 \%)$, ALC $<1.5$ (44.8\%), NLR $>1.8 \quad(93.1 \%)$ and PLT $<150 \mathrm{k}-(65.5 \%)$. (Table 1).

A statically significant higher values of in mean NLR and ANC values were noted in both study groups i.e. deceased versus survivors $(\mathrm{p}=0.022$, $\mathrm{p}=0.032$ respectively). We also observed that the patients who expired had low platelet counts as compared to the survivors $(\mathrm{p}<0.05)$. (Table 2$)$.

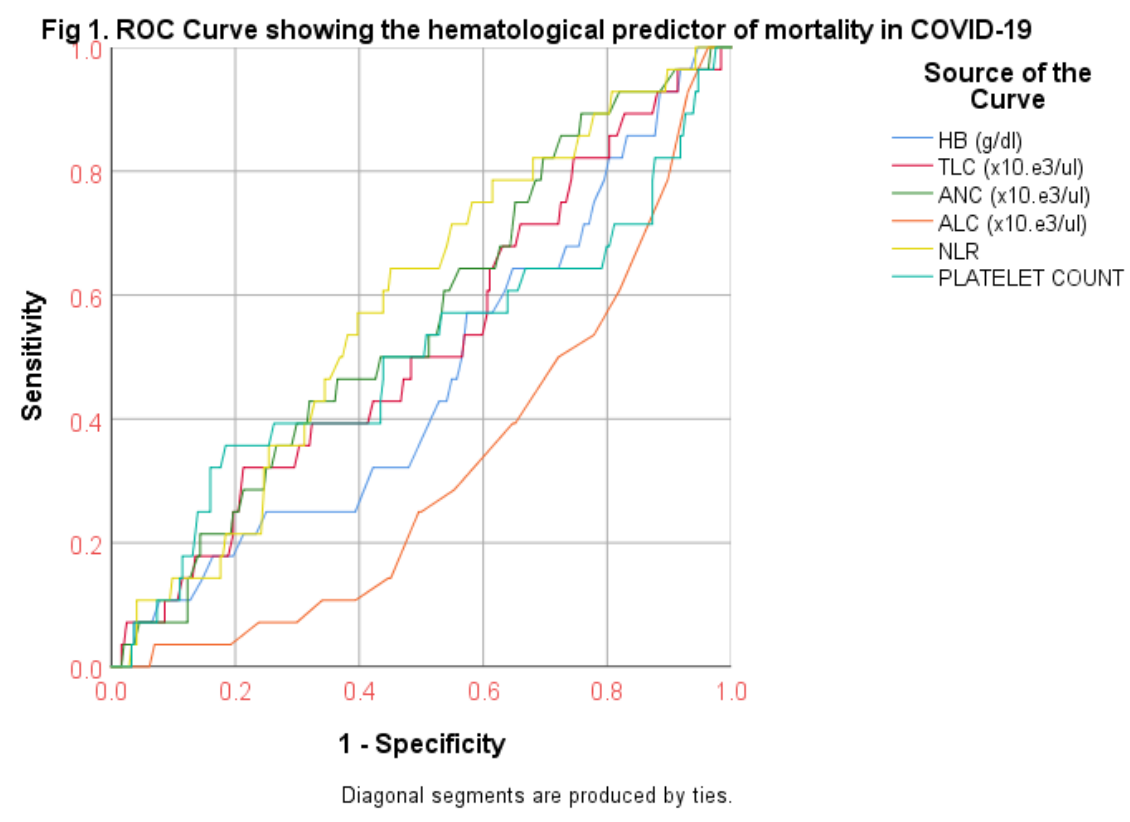

Table (1): Cut-off values for hematological markers with AUC, Sensitivity, and specificity in Corona Virus Disease patients diagnosed by PCR Test.

\begin{tabular}{|l|l|l|l|l|l|l|l|}
\hline Diagnostic test & $\begin{array}{c}\text { Area Under } \\
\text { Curve (AUC) }\end{array}$ & $\begin{array}{c}\text { Cut off } \\
\text { value }\end{array}$ & Std. Error & Sensitivity & Specificity & \multicolumn{2}{|c|}{$95 \%$ CI for AUC } \\
\cline { 5 - 8 } & & & & & $\begin{array}{c}\text { Lower } \\
\text { Bound }\end{array}$ & $\begin{array}{c}\text { Upper } \\
\text { Bound }\end{array}$ \\
\hline Hb\% & 0.464 & $\leq 11$ & 0.05 & 69.1 & 75.8 & 0.31 & 0.52 \\
\hline TLC & 0.52 & $>11$ & 0.06 & 75.9 & 80.4 & 0.38 & 0.63 \\
\hline ANC & 0.615 & $>3.9$ & 0.06 & 86.2 & 79.7 & 0.42 & 0.72 \\
\hline ALC & 0.321 & $\leq 1.5$ & 0.05 & 44.8 & 54.2 & 0.28 & 0.47 \\
\hline NLR & 0.683 & $>1.8$ & 0.06 & 93.1 & 89.5 & 0.44 & 0.78 \\
\hline PLT & 0.551 & $\leq 150$ & 0.06 & 65.5 & 83.1 & 0.34 & 0.59 \\
\hline
\end{tabular}


The test result variable(s): Hemoglobin(Hb (g/dl), Total Leukocytes count (TLC (x10.e3/ul)), Absolutes Neutrophilic count(ANC (x10.e3/ul)), Absolutes Lymphocyte count (ALC (x10.e3/ul), Neutrophil to Lymphocyte Ratio (NLR) and Platelet count (PLT)

Table (2): Difference in hematological markers in COVID-19 in study groups.

\begin{tabular}{|c|c|c|c|c|}
\hline \multirow[b]{2}{*}{ Hematological markers } & $\begin{array}{c}\text { Improved or } \\
\text { (survivors) }\end{array}$ & $\begin{array}{l}\text { Died or (non- } \\
\text { survivors) }\end{array}$ & \multirow[t]{2}{*}{ p-value } & \multirow{2}{*}{ Test of significance } \\
\hline & $(\mathrm{N}=153)$ & $(\mathrm{N}=29)$ & & \\
\hline HB $(g / d l)$ & \multirow{2}{*}{$11.25 \pm 6.41$} & \multirow{2}{*}{$10.9 \pm 2.09$} & \multirow{2}{*}{0.721} & \multirow{2}{*}{ Independent $\mathrm{T}$ Test } \\
\hline Mean \pm SD & & & & \\
\hline TLC (x10.e3/ul) & \multirow{2}{*}{$12.51 \pm 5.89$} & \multirow{2}{*}{$14.06 \pm 5.74$} & \multirow{2}{*}{0.432} & \multirow{2}{*}{ Independent $\mathrm{T}$ Test } \\
\hline Mean \pm SD & & & & \\
\hline ANC (x10.e3/ul) & \multirow{2}{*}{$9.71+5.98$} & \multirow{2}{*}{$11.61+5.41$} & \multirow{2}{*}{0.032} & \multirow{2}{*}{ Independent T Test } \\
\hline Mean \pm SD & & & & \\
\hline ALC (x10.e3/ul) & \multirow{2}{*}{$1.19 \pm 0.85$} & \multirow{2}{*}{$0.88 \pm 0.48$} & \multirow{2}{*}{0.081} & \multirow{2}{*}{ Independent T Test } \\
\hline Mean \pm SD & & & & \\
\hline NLR & \multirow{2}{*}{$13.03 \pm 6.11$} & \multirow{2}{*}{$15.54 \underline{+2.46}$} & \multirow{2}{*}{0.022} & \multirow{2}{*}{ Independent T Test } \\
\hline Mean \pm SD & & & & \\
\hline Platelet count & \multirow[t]{2}{*}{219.46} & \multirow[t]{2}{*}{157.18} & \multirow[t]{2}{*}{0.051} & \multirow{2}{*}{ Mann Whitney U Test } \\
\hline Median & & & & \\
\hline
\end{tabular}

\section{DISCUSSION}

Considering the higher rate of infectivity and mortality due to COVID-19, an early detection of the disease and understanding the prognostic values of the simple tests that are available even at primary and secondary care centers, is the need of time. In present study we noted that the clinical sensitivity of NLR was $93.1 \%$ with Area Under curve on ROC of 0.68. This documents it to be a major prognostic factor in COVID-19 to predict mortality/worst outcome with a followed by absolute neutrophilic count (ANC). A higher TLC, ANC and NLR carry bad prognosis in case of COVID-19. No doubt the definite diagnosis of the COVID-19 is by RT-PCR. Asymptomatic /subclinical patients deteriorate if not properly observed and looked after7. We analyzed the role of complete blood count (CBC) and assessed various hematological parameters for their prognostic values in groups with survivors against those met the unfortunate end of lives with COVID-19. We observed that no significant difference in concentration of hemoglobin in both the groups with different outcome ( $p>0.05)$. However there was a significant difference in indicators i.e. TLC, ANC, ALC, NLR and Platelet counts among the survivors versus non survivors $(p<0.05)$. Similar findings have been reported from a study conducted in Ankara Turkey [9]. Another study from Karachi Pakistan reported 364 Covid-19 patients, with $27.7 \%$ mortality. They assessed likewise patients in survivors and non-survivor groups. They reported that there was a significant difference in TLC $(\mathrm{p}<0.001)$, ANC $(\mathrm{p}<0.001)$ and ALC $(p<0.001)$ [10]. Their findings were in concordance with our results.

Another retrospective study by the same principal author, from different teaching hospitals of Karachi, reported a significant difference of hematological markers in groups survived versus expired. They reported a significant difference in mean $\mathrm{Hb} \%$ (p-0.03), TLC, ANC, ALC and NLR (p-0.001 each) [11]. Again their findings do match our results for WBC and platelet but we could not find a significant difference in mean $\mathrm{Hb} \%$ of the survivors versus deceased.

Other researcher findings do support the fact that NLR is diagnostic and prognostic marker in viral infections (AUC $=0.710$ ) [12]. Ai-Ping Yang et al reported NLR with AUC of 0.743 on ROC to determine the outcome of the seriously ill patients due to COVID-19 to document the prognostic values of NLR [13] (Table 3). Their findings closely match our results. Moreover the Sun et al reported the AUC of 0.88 for NLR that was recorded in seriously ill COVID-19 patients who met the worst outcome [14].

Likewise the AUC of the absolute neutrophilic count (ANC) was 0.6 and was significantly higher in group with case fatality. Therefore ANC can also be used as prognostic marker in 
COVID-19. Notably, a study published in American Journal of Hematology reported high leukocyte count in COVID-19 ICU patients with severe complications with median peak ANC of $11600 / \mathrm{cmm} 3$ as compared to non-ICU patients without complications $(\mathrm{p}<0.001)$ [15].

Platelet count itself is a marker in COVID mortality. We observed an AUC of 0.55 for low platelet count in patient died of COVID-19. Our findings are in concordance with findings of the Yang et al who also reported thrombocytopenia in all deceased patients due to Covid-19 in their target population [16]. The comparison of the finding with other national and international studies is well documented in table 3 .

Table (3): Comparison of difference in AUC of different hematological markers in groups (survivor vs deceased)with other research studies

\begin{tabular}{|c|c|c|c|c|c|c|c|}
\hline $\begin{array}{c}\text { Hematological } \\
\text { parameters }\end{array}$ & $\begin{array}{l}\text { Area Under } \\
\text { Curve (AUC)- } \\
\text { Present study }\end{array}$ & $\begin{array}{c}\text { Usul E et al } \\
\text { [9] }\end{array}$ & $\begin{array}{l}\text { Yang AP et } \\
\text { al [13] }\end{array}$ & $\begin{array}{c}\text { Sun } S \text { et al } \\
{[\mathbf{1 4}]}\end{array}$ & $\begin{array}{l}\text { Asghar MS } \\
\text { et al [10[ }\end{array}$ & $\begin{array}{l}\text { Asghar MS } \\
\text { et al [11] }\end{array}$ & $\begin{array}{c}\text { Yang et al } \\
\text { [16] }\end{array}$ \\
\hline HB & $\begin{array}{l}0.464 \\
\mathrm{p}>0.05\end{array}$ & $\begin{array}{l}0.612 \\
\mathrm{p}<0.05\end{array}$ & & & & $\mathrm{p}<0.05$ & \\
\hline TLC & $\begin{array}{c}0.52 \\
p>0.05\end{array}$ & $\begin{array}{l}0.828 \\
\mathrm{p}<0.05\end{array}$ & & & $\begin{array}{c}0.709-0.786, \\
p<0.05\end{array}$ & $p<0.05$ & \\
\hline ANC & $\begin{array}{l}0.615 \\
\mathrm{p}<0.05\end{array}$ & 0.826 & & & $\mathrm{p}<0.05$ & $\mathrm{p}<0.05$ & \\
\hline ALC & $\begin{array}{l}0.321, \\
p<0.05\end{array}$ & $p>0.05$ & $\begin{array}{c}0.714, \\
p<0.05\end{array}$ & & $\mathrm{p}<0.05$ & $\mathrm{p}<0.05$ & \\
\hline NLR & $\begin{array}{l}0.683 \\
p<0.05\end{array}$ & 0.739 & $\begin{array}{l}0.743 \\
p<0.05\end{array}$ & $\begin{array}{c}0.925, \\
\mathrm{p}<0.05\end{array}$ & & $\begin{array}{c}0.841-0.860, \\
p<0.05\end{array}$ & \\
\hline PLT & $\begin{array}{l}0.551, \\
\mathrm{p}<0.05\end{array}$ & $\begin{array}{l}0.618 \\
p>0.05\end{array}$ & $\begin{array}{l}0.784, \\
\mathrm{p}<0.05\end{array}$ & & & & $\mathrm{p}<0.05$ \\
\hline
\end{tabular}

\section{CONCLUSION}

Hence we concluded that the clinical sensitivity as measured by (AUC) for hematological markers i.e. NLR, ANC and Platelet count have strong tie between the disease state with mortality and the disease state group without complications. Leukocytosis, neutrophilia, lymphopenia, with high NLR, low platelet count and hyperferritinemia are worst prognostic markers in COVID-19.

\section{Limitations of the study:}

The limitation of this study was the low sample size. Studies executed with larger sample size are recommended. The way forward is to suggest future studies should cover large population with representation of all sectors to have a better outcome to predict/suggest the findings for decision making by the competent authorities to prevent disastrous pandemic.

Funding: None.

Conflicts of interest: The authors declare that there is no conflict of interest.
Ethical approval: Was granted by the Institutional Review Board and informed consent was obtained for inclusion in the study.

\section{REFERENCES}

1. Woo PC, Lau SK, Huang Y, Yuen KY. Coronavirus diversity, phylogeny and interspecies jumping. Exp. Biol. Med. (Maywood) 2009; 234(10): 1117-1127.

2. Weston S, Frieman MB. COVID-19: knowns, unknowns, and questions. mSphere. 2020; 5(2): e00203-20. [PubMed] DOI: $10.1128 / \mathrm{mSphere.}$ 00203-20.

3. World Health Organization. 2019-nCoV outbreak is an emergency of international concern. 2020. http://www.euro.who.int/en/healthtopics/emergencies/pages/news/news/2020/01/201 9-ncov-outbreak-is-an-emergency-ofinternational-concern (access Feb 16, 2020).

4. Centre of Disease Control-Confirmed cases. https://www.ecdc.europa.eu/en/geographicaldistribution-2019-ncov-cases. Retrieved 28th Nov 2020.

5. "Coronavirus in Pakistan - Confirmed Cases". www.covid.gov.pk/. Retrieved 29th Nov 2020. 
6. WHO Use of laboratory methods for SARS diagnosis. World Health Organization, Geneva. 2020.

7. Letícia-de-Oliveira-Toledo S, Sousa-Nogueira L, das-Graças-Carvalho M, Romana-Alves-Rios D, de-Barros-Pinheiro M. COVID-19: Review and hematologic impact. Clin Chim Acta. 2020; 510:170-176. doi:10.1016/j.cca.2020.07.016.

8. Fan BE. Hematologic parameters in patients with COVID-19 infection: a reply. Am J Hematol. 2020; 95(8): E215. doi:10.1002/ajh.25847.

9. Usul E, Şan İ, Bekgöz B, Şahin A. Role of hematological parameters in COVID-19 patients in the emergency room. Biomark Med. 2020; 14(13):1207-1215. doi:10.2217/bmm-2020-0317.

10. Asghar MS, Haider Kazmi SJ, Khan NA, Akram M, Hassan M, Rasheed U, Ahmed Khan S. Poor Prognostic Biochemical Markers Predicting Fatalities Caused by COVID-19: A Retrospective Observational Study From a Developing Country. Cureus. 2020;12(8):e9575. Published 2020 Aug 5. doi:10.7759/cureus.9575.

11. Asghar MS, Khan NA, Haider Kazmi SJ, Ahmed A, Hassan M, Jawed R et al. Hematological parameters predicting severity and mortality in COVID-19 patients of Pakistan: a retrospective comparative analysis. J Community Hosp Intern Med Perspect. 2020 Oct 29; 10(6):514-520.

12. Zhang Y, Zou P, Gao H, Yang M, Yi P, Gan J, et al. Neutrophil-lymphocyte ratio as an early new marker in AIV-H7N9-infected patients: a retrospective study. Ther Clin Risk Manag. 2019; 15:911-19.

13. Yang AP, Liu JP, Tao WQ, Li HM. The diagnostic and predictive role of NLR, d-NLR and PLR in COVID-19 patients. Int Immunopharmacol. 2020; 84:106504.

14. Sun S, Cai X, Wang H, He G, Lin Y, Lu B, et al. Abnormalities of peripheral blood system in patients with COVID-19 in Wenzhou, China. Clin Chim Acta. 2020 Aug; 507():174-180.

15. Fan BE, Chong VCL, Chan SSW, Lim GH, Guan $\mathrm{K}$, Lim E. Hematologic parameters in patients with COVID-19 infection. Am J Hematol. 2020; 95:E131-53.

16. Yang S, Yang Q, Wang Y, Wu Y, Xu J, Yu Y et al. Thrombocytopenia and Its Association with Mortality in Patients with COVID-19. J Thromb Haemost. 2020; 18:1469-1472. 